\title{
Non-aneurysmal non-traumatic subarachnoid hemorrhage: patient characteristics, clinical outcome and prognostic factors based on a single-center experience in 125 patients
}

\author{
Juergen Konczalla*, Johannes Platz, Patrick Schuss, Hartmut Vatter, Volker Seifert and Erdem Güresir
}

\begin{abstract}
Background: Subarachnoid hemorrhage $(\mathrm{SAH})$ is mainly caused by ruptured cerebral aneurysms but in up to 15\% of patients with SAH no bleeding source could be identified. Our objective was to analyze patient characteristics, clinical outcome and prognostic factors in patients suffering from non-aneurysmal SAH.

Methods: From 1999 to 2009, data of 125 patients with non-aneurysmal SAH were prospectively entered into a database. All patients underwent repetitive cerebral angiography. Outcome was assessed according to the modified Rankin Scale (mRS) (mRS 0-2 favorable vs. 3-6 unfavorable). Also, patients were divided in two groups according to the distribution of blood in the CT scan (perimesencephalic and non-perimesencephalic SAH).

Results: 106 of the 125 patients were in good WFNS grade (I-III) at admission (85\%). Overall, favorable outcome was achieved in 104 of 125 patients (83\%). Favorable outcome was associated with younger age $(P<0.001)$, good admission status $(P<0.0001)$, and absence of hydrocephalus $(P=0.001)$.

73 of the 125 patients suffered from perimesencephalic SAH, most patients (90\%) were in good grade at admission, and 64 achieved favorable outcome.

52 of the 125 patients suffered from non-perimesencephalic SAH and 40 were in good grade at admission. Also 40 patients achieved favorable outcome.

Conclusions: Patients suffering from non-aneurysmal SAH have better prognosis compared to aneurysm related SAH and poor admission status was the only independent predictor of unfavorable outcome in the multivariate analysis. Patients with a non-perimesencephalic SAH have an increased risk of a worse neurological outcome. These patients should be monitored attentively.
\end{abstract}

Keywords: Non-aneurysmal, Aneurysm, Perimesencephalic, Non-perimesencephalic, Prepontine, Subarachnoid hemorrhage, SAH

\section{Background}

Spontaneous subarachnoid hemorrhage (SAH) is usually caused by rupture of an intracranial aneurysm. In up to $15 \%$ of patients with spontaneous $\mathrm{SAH}$, no bleeding source can be identified despite of repetitive radiological imaging [1-5]. In 20 to $70 \%$ of patients with angiography negative $\mathrm{SAH}$ the blood distribution is described as perimesencephalic or prepontine [6]. Patients with perimesencephalic

\footnotetext{
* Correspondence: J.Konczalla@med.uni-frankfurt.de

Department of Neurosurgery, Johann Wolfgang Goethe-University Frankfurt am Main, Schleusenweg 2-16, 60528 Frankfurt am Main, Germany
}

$\mathrm{SAH}$ are considered to achieve a good outcome and to have a lower risk of rebleeding [6,7]. However, data on patients suffering from spontaneous non-aneurysmal SAH is limited. There are a few studies reporting on a limited number of patients [2,8-12]. Therefore, the aim of the present study was to investigate the clinical course and outcome in patients suffering from non-aneurysmal spontaneous SAH.

\section{Methods}

After exclusion of patients with traumatic SAH we reviewed 1046 consecutive patients with SAH admitted 
in our department between 1999 and 2009. SAH was confirmed on computed tomography (CT) and/or lumbar puncture. We identified 125 patients (12\%) with a spontaneous non-aneurysmal SAH after diagnostic workup. Information, including patient characteristics, treatment, radiological features, and outcome was prospectively entered into a computerized database.

In our hospital algorithm all patients with SAH underwent angiography and since 2002 at least four-vessel 3D digital subtraction angiography (DSA) to rule out intracranial sources for SAH. In case of a negative initial angiography, DSA was repeated after 14 days. Additionally, magnetic resonance imaging (MRI) of the spine was performed to rule out any spinal bleeding sources. In patients without typical perimesencephalic distribution of blood a third DSA was performed 3 months after SAH. Patients were stratified according to the distribution of blood into two groups, perimesencephalic (PM) and non-perimesencephalic (NPM) SAH.

The study was approved by the local ethics committee of Goethe-University hospital Frankfurt.

We defined a perimesencephalic hemorrhage according to van Gijn et al. [7] and Rinkel et al. [13]. Hemorrhages located in front of the brain stem, mainly in the interpeduncular cistern, with or without extension to the ambient, chiasmatic and horizontal part of the Sylvian cisterns, were classified as perimesencephalic $\mathrm{SAH}$, whereas in non-perimesencephalic hemorrhages blood was not located mainly in the interpeduncular cistern, but in the Sylvian cistern, interhemispheric cistern, convexity or a CT-negative and lumbar puncture positive bleeding (see Figure 1). Our treatment protocol includes the application of nimodipine in all patients with $\mathrm{SAH}$ from the day of admission and has been described in detail previously [14]. Patients were monitored daily with transcanial Doppler ultrasound (TCD) at least up to day twelve after bleeding. Patients with a non-perimesencephalic SAH without suspicion of delayed cerebral ischemia (DCI) and intubated patients with a perimesencephalic $\mathrm{SAH}$ routinely received on day $7 \pm 2$ after ictus a CT or MRI. We defined DCI based on the Vergouwen-definitions [15]; in brief, the occurrence of focal neurological impairment, which cannot be attributed to other causes. For comatose and sedated patients, in which a DCI couldn't be monitored, instead of DCI a proximal arterial diameter reduction of more than $66 \%$ was defined as cerebral vasospasm. In our hospital algorithm patients received an invasive diagnostic and therapeutic management (angioplasty and/or intraarterial nimodipine) [14], but in this cohort only one patient received an angioplasty with two intraarterial nimodipine therapies, and another patient received an one-time intraarterial nimodipine treatment.

Patients were divided into good grade (WFNS grades I III) versus (vs.) poor grade (WFNS IV - V) on admission.
Outcome was assessed according to the modified Rankin Scale (mRS) and stratified into favorable (mRS 0-2) vs. unfavorable (mRS 3-6) after 6 months.

In non-comatose patients hydrocephalus was defined as clinical deterioration (like deterioration from somnolence to stupor) and enlargement of the temporal horns of more than $2 \mathrm{~mm}$. In comatose patients the enlargement of the temporal horns was defined as hydrocephalus and normally an external ventricular drainage was placed.

\section{Statistical analysis}

Unpaired t-test was used for parametric statistics. Categorical variables were analyzed in contingency tables using the $\mathrm{Chi}^{2}$ test. Results with a $P$ value $<0.05$ were considered statistically significant. Variables with significant probability values on univariate analysis were considered as potentially independent variables on multivariate analysis. A backward stepwise method was used to construct multivariate logistic regression models with the inclusion criterion of $P<0.05$. All calculations were made with standard commercial software (SPSS Institute, Inc.).

\section{Results}

\section{Patient characteristics}

After diagnostic workup in 125 of 1046 patients (12\%) with spontaneous SAH no bleeding source was identified and these patients were included in this study. The mean age was 56 years. Men were more frequently affected by non-aneurysmal SAH (70\%). Patient characteristics are detailed in Table 1 . From $07 / 1999$ to $12 / 200224$ patients had a non-aneurysmal SAH. From $1 / 2003$ to 6/2006 50 patients (108\% increase in comparison to the period before) had a non-aneurysmal SAH and from 07/2006 to 12/ 200951 patients (113\% increase) had a non-aneurysmal $\mathrm{SAH}$. Also the rate of patients with systemic anticoagulation or platelet inhibition increased from $4 \%$ to $22 \%$ over the periods (see Figure 2).

\section{Clinical presentation}

Overall, 106 patients (85\%) were in good clinical condition at admission.

40 of 52 patients (77\%) suffering from nonperimesencephalic SAH had good admission status compared to 66 of 73 patients (90\%) suffering from perimesencephalic SAH $(P=0.07)$. In 54 patients $(43 \%)$ an arterial hypertension $(\geq 140 \mathrm{mmHg}$ systolic blood pressure) was diagnosed (see Table 1). Like for anticoagulants the rate of patients with hypertension increased over the periods (from 33\% to 55\%) (see Figure 2).

\section{Imaging results}

Overall, initially in 137 patients a non-aneurysmal SAH was detected by CT or lumbar puncture. In twelve of these 137 patients (9\%) a bleeding source was detected 


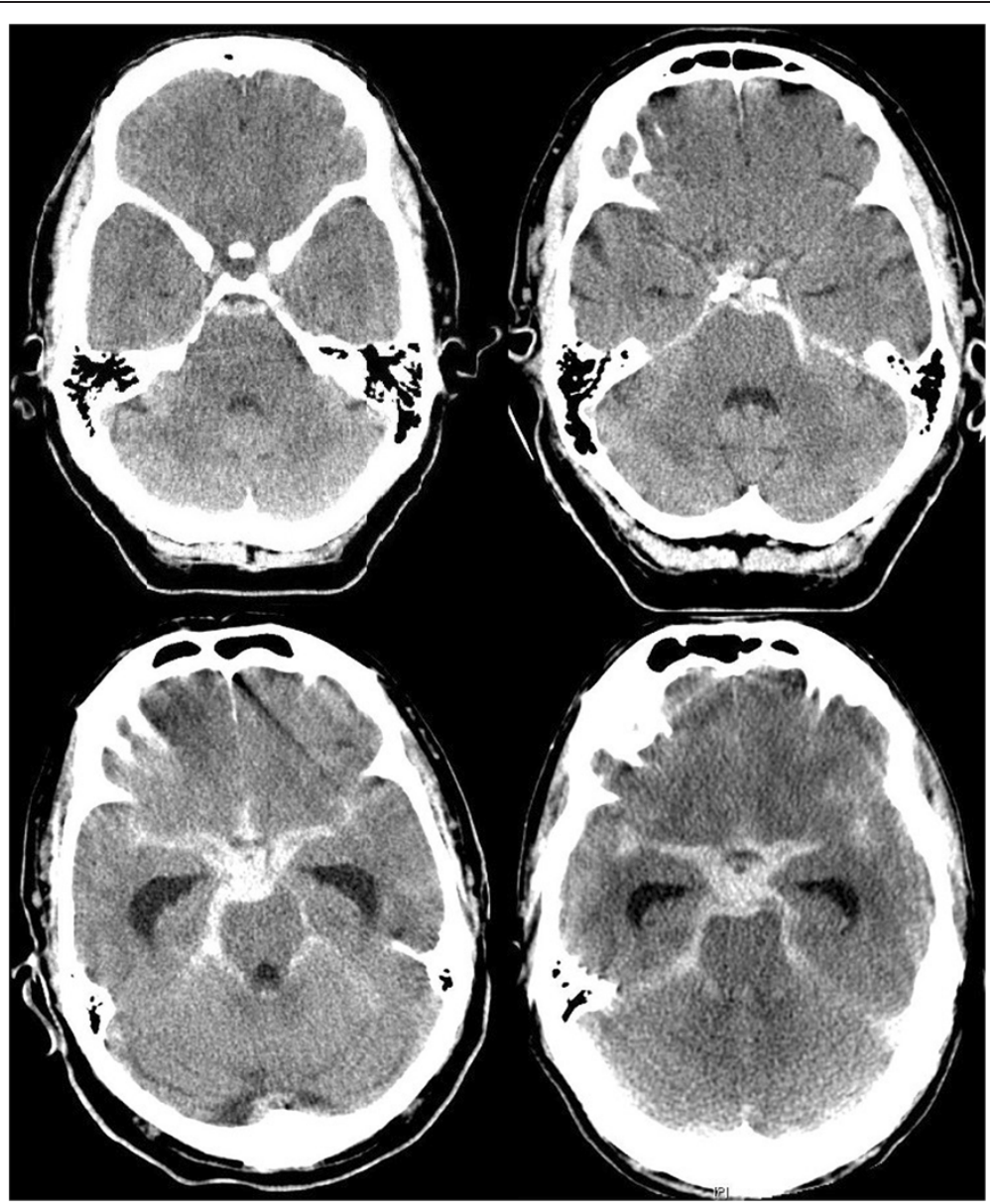

Figure 1 Perimesencephalic and non-perimesencephalic SAH. In the upper row $\subset$ T scans of two patients with perimesencephalic SAH are illustrated. Whereas in the top left-hand the center of the hemorrhage is located anterior the brainstem, in the top right-hand corner the hemorrhage is located more left-sided. In the lower row CT scans of two patients with non-perimesencephalic SAH are illustrated. In both patients the bleedings are not only located anterior the midbrain, but also enlarging into the sylvian and interhemispheric cisterns. Also in contrast to the upper row these patients had a hydrocephalus with enlargement of the temporal horns.

Table 1 Patient characteristics

\begin{tabular}{|c|c|c|c|c|}
\hline Characteristics & Non-aneurysmal SAH (\% of total pat.) & Perimesencephalic SAH (\%) & Non-perimesencephalic SAH (\%) & $P$-value* \\
\hline No. of patients & 125 & $73(58 \%)$ & $52(42 \%)$ & NS \\
\hline Mean age $+/-$ SD & $56.4 \pm 13.1$ & $54.6 \pm 12.1$ & $58.8 \pm 14.2$ & NS \\
\hline Female sex & $38(30 \%)$ & $18(25 \%)$ & $20(38 \%)$ & NS \\
\hline Mean WFNS at admission & $\|$ & $\|$ & $\|$ & \\
\hline WFNS I-III at admission & $106(85 \%)$ & $66(90 \%)$ & $40(77 \%)$ & NS \\
\hline Early hydrocephalus & $36(29 \%)$ & $18(25 \%)$ & $18(35 \%)$ & NS \\
\hline Arterial hypertension & $54(43 \%)$ & $28(38 \%)$ & $26(50 \%)$ & NS \\
\hline Mean mRS & 1 & 1 & 2 & \\
\hline Favorable outcome & $104(83 \%)$ & $64(88 \%)$ & $40(77 \%)$ & NS \\
\hline Death after 6 months & $12(10 \%)$ & $5(7 \%)$ & $7(13 \%)$ & NS \\
\hline VP-shunt & $12(10 \%)$ & $5(7 \%)$ & $7(13 \%)$ & NS \\
\hline
\end{tabular}




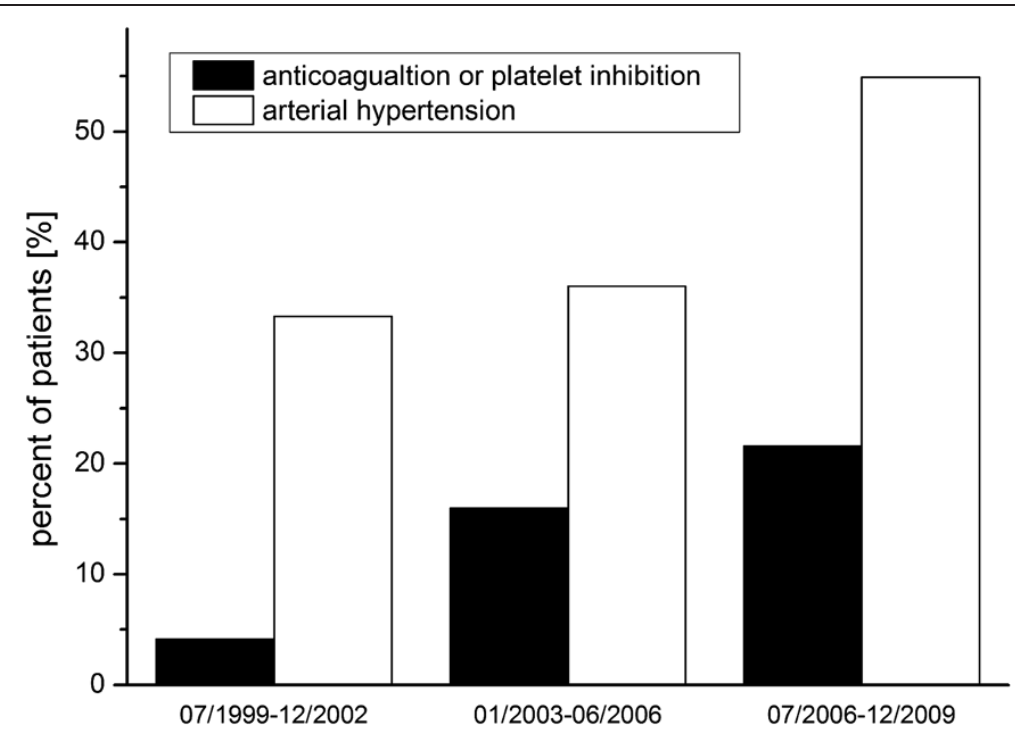

Figure 2 Rate of arterial hypertension and anticoagulation. From 07/1999 to 12/2009 we had an increasing rate of patients with arterial hypertension (from $33 \%$ to $55 \%$ ). Also the rate of patients with systemic anticoagulation and/or platelet inhibition increased in this period from $4 \%$ to $22 \%$.

by DSA (11 patients) or MRI (1 patient). Five aneurysms of the anterior circulation, four aneurysms of the posterior circulation, one cerebellar AVM and one AV-fistula were detected in the following DSA and a spinal pathology in the MRI. These patients were excluded from this study. Overall, 52 of the 125 patients (42\%) suffered from non-perimesencephalic, and 73 patients (58\%) from perimesencephalic SAH (see Figure 1 and Table 1). 12 patients $(10 \%)$ had a CT-negative/lumbar puncture positive SAH. The initial angiograms of these patients were all negative for a vasoconstriction. $38 \%$ of the patients with a non-perimesencephalic SAH had a SAH according Fisher type 3 [16]. Only 2 patients (4\%) had a convexity-located SAH. Respectively, one woman with a high fronto-parietal SAH and one man with a temporomesial SAH.

\section{Early vs. late hydrocephalus}

Overall, 36 patients (29\%) suffered from early hydrocephalus at admission and underwent a placement of a ventricular drain. 12 of the 36 patients (10\%) developed posthemorrhagic hydrocephalus and underwent a placement of a ventriculoperitoneal shunt (VP-shunt). 7 patients (13\%) with non-perimesencephalic SAH vs. 5 patients (7\%) with perimesencephalic SAH developed late hydrocephalus over the course of treatment.

23 patients (22\%) with favorable outcome vs. 13 patients (62\%) with unfavorable outcome suffered from early hydrocephalus $(P<0.001, \mathrm{OR}=0.2,95 \% \mathrm{CI}=0.1-0.5$; Table 2$)$.

Neurological outcome and delayed cerebral ischemia Overall, favorable outcome was achieved in 104 patients $(83 \%)$.
More precise, this favorable outcome was achieved in 64 patients (88\%) of PM-SAH vs. 40 patients (77\%) in NPMSAH $(P=0.18) .5$ patients in PM-SAH $(7 \%)$ vs. 7 patients in NPM-SAH (13\%) died during the observation period $(P=0.35)$ (Table 1$)$. In 18 patients $(14 \%)$ a delayed cerebral ischemia (DCI) [15] was observed. Patients with a NPMSAH suffered more often a DCI (19\%) compared to patients with PM-SAH (11\%), but no statistical significant difference between these groups could be determined $(P>$ $0.05, \mathrm{OR}=0.5,95 \% \mathrm{CI}=0.2-1.4)$. Also sex and arterial hypertension did not influence the outcome.

Patients, who achieved favorable outcome were younger compared to patients, who achieved unfavorable outcome (55 vs. 66 years; $P<0.001$ ).

Patients presented in a good clinical status at admission achieved significantly more often a favorable outcome compared to patients with a poor admission status (92\% vs. $48 \% ; P<0.0001, \mathrm{OR}=13.2,95 \% \mathrm{CI}=4-40$; Table 2 ).

\section{Multivariate analysis}

Of those variables that influenced clinical outcome of patients at 6 months after discharge in the univariate analyses (age $>65$ years, hydrocephalus and poor admission status), only the variable "poor admission status" $(P<$ 0.001, $\mathrm{OR}=13.2,95 \% \mathrm{CI}=4-40$ ) remained significant as an independent predictor of unfavorable outcome in the multivariate regression model (Nagelkerke`s $R^{2}=0.26$ ).

\section{Discussion}

In up to $15 \%$ of patients suffering from SAH, no source of bleeding could be identified [2,6,8,17-19]. The majority of patients with non-aneurysmal SAH are in good clinical condition at admission $[2,6,8,18,19]$. Non-aneurysmal and 
Table 2 Outcome of non-aneurysmal SAH

\begin{tabular}{|c|c|c|c|c|}
\hline Characteristics & Favorable outcome & Unfavorable outcome & OR $(95 \% \mathrm{Cl})$ & $P$-value* \\
\hline Number of patients & $104(83 \%)$ & $21(17 \%)$ & & \\
\hline Mean age $+/-$ SD & $54.5 \pm 12.7$ & $65.7 \pm 11.4$ & $11.2(5-17)$ & $<0.001$ \\
\hline Good admission status & $96(92 \%)$ & $10(48 \%)$ & $13.2(4-40)$ & $<0.0001$ \\
\hline \multirow[t]{2}{*}{ Early hydrocephalus } & $23(22 \%)$ & $13(62 \%)$ & $0.17(0.06-0.47)$ & $<0.001$ \\
\hline & & & $5.7(2.1-15)$ & \\
\hline Arterial hypertension & $45(43 \%)$ & $9(43 \%)$ & & NS \\
\hline Female sex & $29(28 \%)$ & $9(43 \%)$ & & NS \\
\hline
\end{tabular}

*unpaired t-test for parametric statistics and $\mathrm{Chi}^{2}$ test for categorical variables; WFNS World Federation of Neurological Societies, OR odds ratio; Cl confidence interval; NS not significant $(\mathrm{p}>0.05)$.

especially perimesencephalic SAH is often associated with favorable outcome compared to aneurysmal SAH $[1,7,13,20]$. However, data on patients with spontaneous non-aneurysmal SAH are commonly based on case series and is therefore scarce $[2,6,8-10,17,19,21]$.

We therefore analyzed our neurovascular database concerning patients suffering from non-aneurysmal SAH. In the present series, $12 \%$ of patients $(n=125)$ with SAH had no source of bleeding after repeated cerebral angiograms and MRI of the spine.

\section{Clinical presentation}

Patients suffering from non-aneurysmal SAH are usually in good clinical condition $[2,6,8,18,19]$. This could be confirmed in the present study, in which $85 \%$ of the patients were in a good status at admission (WFNS grade I - III). However, patients with a perimesencephalic (PM) SAH were in a better status at admission compared to patients with a non-perimesencephalic (NPM) SAH (90\% vs. 77\%), not reaching statistically significance $(P<0.07)$. In both subgroups, PM-SAH and NPM-SAH, men are affected more likely compared to women (for PM-SAH in $75 \%$ and for NPM-SAH in 62\%).

Despite the technological improvements of DSA, we found increasing cases of angiography-negative SAH in our analysis. This could be explained by the increasing numbers of patients with systemic anticoagulation or platelet inhibition (see Figure 2). However, data for antithrombotic therapy in non-aneurysmal SAH is scarce, but describing higher blood amount and rebleeding rates [22-24]. A further reason for the growing numbers of angiography-negative SAH could be the increasing numbers of arterial hypertension (see Table 1).

\section{Imaging results}

An intracranial source of hemorrhage was identified in eleven of 137 patients (8\%) by DSA. In one patient (1\%) after aneurysm-negative DSA in the spinal MRI a pathology as source of hemorrhage was identified. Compared to other published data with series of more than 50 patients this rate is very similar $(7 \%-18 \%)[5,17,25,26]$. Some studies described lower rates, but repeated angiography were done in series with less than 50 patients $[21,27]$.

A recently published study reported a significantly lower rate of rebleeding in patients with perimesencephalic $\mathrm{SAH}$ compared to patients with NPM-SAH [28]. And rebleeding is the most important preventable cause of unfavourable outcome in patients suffering from spontaneous SAH [29]. However, in patients with aneurysm-negative baselineDSA, repeat angiography is necessary in order to detect a potential bleeding source and to prevent rebleeding [25,30]. Due to the small, but substantial risk of neurological worsening after DSA, in PM-SAH a non-invasive angiography by MRI or CT might be sufficient [3-5,31]. In patients with a Fisher type 3 pattern of hemorrhage a false-negative DSA rate up to $46 \%$ was found [26], therefore a repeated DSA should be performed in NPM-SAH [7,26,31]. In our treatment protocol all patients receive two DSA and MRI of the whole spine, resulting in only one rebleeding after this diagnostic work-up. In twelve patients (9\%) a bleeding source was detected. For sulcal convexity SAH in up to $87 \%$ of the patients the combination of MRI and DSA could identify the aetiology of bleeding, like reversible cerebral vasoconstriction syndrome (RCVS or Call-Fleming), cerebral amyloid angiopathy or posterior reversible encephalopathy syndrome (PRES), which represented more than $50 \%$ of etiological mechanisms [12]. Unfortunately, in our two cases with sulcal convexity SAH an aetiology wasn't diagnosed. In the present series after diagnostic work-up 125 patients had a spontaneous angiogram-negative SAH.

\section{Early vs. late hydrocephalus}

In both groups approximately $30 \%$ of the patients had hydrocephalus at admission, which is higher compared to other series $(5-25 \%)[6,8,32]$. Despite the higher rate of early hydrocephalus, the necessity of permanent shunt placement (10\%) was similar to previous reports (3 $13.5 \%)[6,8,21,32]$.

However, incidence of shunt dependency did not differ significantly in patients with PM-SAH compared to patients with NPM-SAH. 


\section{Neurological outcome}

Non-aneurysmal and especially perimesencephalic SAH is associated with favorable outcome compared to aneurysmal $\mathrm{SAH}[1,7,13,20]$. In the present series, favorable outcome was also achieved in a high number of patients (83\%), with a trend towards a better outcome in the PM-SAH group (88\% vs. $77 \%$ in NPM-SAH) and also a trend towards a lower incidence of DCI (11\% in PM-SAH vs. 19\% in NPM$\mathrm{SAH}$ ). Nayak et al. and Woznica et al. also identified different outcomes of non-aneurysmal SAH according to the blood distribution [18,33]. Although it is taught, that there are only exceptions to a cerebral vasospasm (CVS), in this study $11 \%$ of the patients with PM-SAH developed a DCI. Severe vasospasms also occurred in non-aneurysmal $\mathrm{SAH}$, requiring endovascular intervention [34]. Therefore, clinical outcome of patients with a PM-SAH seems to be better. This also may be due to the lower risk of vasospasm or cerebral ischemia. In the present univariate analysis, early hydrocephalus and poor admission status were significantly associated with unfavorable outcome. Dalyai et al. report a higher risk for hydrocephalus and cerebral vasospasm in the NPMSAH group compared to PM-SAH patients [25]. However, in the multivariate analysis the only independent predictor for unfavorable outcome in patients with non-aneurysmal SAH was "poor admission status" $(P<$ $0.0001, \mathrm{OR}=13.2,95 \% \mathrm{CI}=4-40$ ).

The sex-specific prevalence for a non-aneurysmal SAH is inconsistent and varies from female predominance $[6,19]$, no predominance [32], to male predominance $[2,8,21]$, like in our series, but this doesn't influence the outcome (see Table 2).

\section{Comparison with aneurysmal SAH}

In the present series of non-aneurysmal SAH the mean age (56 years) was similar compared to data of the International Subarachnoid Aneurysm Trial (ISAT) [35] (52 years) or the data of the Barrow Ruptured Aneurysm Trial (BRAT) [36] (53-54 years).

Unlike aneurysmal SAH in the present series more men than women were affected by non-aneurysmal SAH; detailed in Table 3.

Although we didn't know the cause and subsequent pathophysiology of a non-aneurysmal SAH, the patients had a better outcome compared to aneurysmal SAH $(P \sim$ 0.01 ; Table 3$)$. We also detected a reduced risk of DCI compared to DID in ISAT $(P<0.01$; Table 3$)$, which could be one reason for the better outcome. In the light of expected higher number of DCI (including angiographic severe vasospasm) than DID (only neurological deficit and separate data for severe angiographic vasospasm) this fact may be reinforced, when angiographic vasospasm will be excluded from the present data. Especially patients with a NPM-SAH, and a trend towards higher risk of DCI compared to PM-SAH, should be monitored attentively.

\section{Limitations}

The study has several limitations. Statistical analysis was retrospectively performed and conducted from a single center, but the data was collected prospectively. Due to the retrospective design there are the typical restrictions such as the lack of data not documented initially in the medical records. Most of our patients are referred to us from other hospitals, therefore the documentation of the initial blood pressure is often missing and only arterial

Table 3 Comparison of non-aneurysmal SAH vs. ISAT/BRAT-data

\begin{tabular}{|c|c|c|c|c|c|c|c|}
\hline Characteristics & ISAT 2002 & OR $(95 \% \mathrm{Cl})$ & $P$-value * & non-aneurysmal SAH & BRAT 6mon & OR $(95 \% \mathrm{Cl})$ & $P$-value * \\
\hline No. of patients & 2143 & & & 125 & 471 & & \\
\hline Mean age & 52 & & & $56.4 \pm 13.14$ & 53 to 54 & & \\
\hline Male gender & 799 (37\%) & $3.9(2.6-5.7)$ & $<0.0001$ & $87(70 \%)$ & $139(30 \%)$ & $5.5(3.6-8.4)$ & $<0.0001$ \\
\hline \multirow[t]{3}{*}{ WFNS/HH I-III at admission } & $2018(94 \%)$ & $0.35(0.2-0.6)$ & $<0.0001$ & $106(85 \%)$ & $380(81 \%)$ & & NS \\
\hline & & & & Outcome & & & \\
\hline & ISAT 2002 & & & & BRAT 6mon & & \\
\hline No. of patients & 1594 & & & 125 & 341 & & \\
\hline Favourable outcome (mRS 0-2) & $1161(73 \%)$ & $1.85(1.1-3.0)$ & 0.011 & $104(83 \%)$ & $239(70 \%)$ & $2.1(1.3-3.6)$ & $<0.01$ \\
\hline \multirow[t]{2}{*}{ Death } & $145(9 \%)$ & $1.1(0.6-2.0)$ & NS & $12(10 \%)$ & & & \\
\hline & ISAT 2009 & & & & & & \\
\hline $\mathrm{DID} / \mathrm{DCl}$ & 415 (25\%) & $2.0(1.2-3.3)$ & $<0.01$ & 18 (14\%) & & & \\
\hline
\end{tabular}

*unpaired t-test for parametric statistics and $\mathrm{Chi}^{2}$ test for categorical variables vs. ISAT/BRAT; WFNS World Federation of Neurological Societies, OR odds ratio; Cl confidence interval; NS: not significant ( $>$ > 0.05); ISAT 2002: comparison with data from Molyneux et al. [35]; ISAT 2009: comparison with data from Rivero-Arias et al. [37]; BRAT 6mon: comparison with 6 months outcome data from Spetzler et al. [36].

DID delayed ischemic neurological deficit according to the ISAT 2009 data [37]; DCI delayed cerebral ischemia, according the Vergouwen definitions [15]. 
hypertension ( $\geq 140 \mathrm{mmHg}$ systolic blood pressure) could be examined. Also a control group is absent. The followup examination was conducted 6 months after ictus. To reduce this limitation a comparison with two prospective multicenter studies was performed, also using follow-up at least 6 months after ictus [35-37]. Despite the good outcome, defined by mRS $0-2$, a further investigation with long-term outcome using a more complex scale, dividing functional, social and psychological outcome, would be of great interest.

\section{Conclusion}

Perimesencephalic and non-perimesencephalic SAH have similar presentation status. Favorable outcome is achieved in most patients. Poor admission status was the only independent predictor of unfavorable outcome in patients with spontaneous non-aneurysmal SAH in the multivariate analysis. In this large study (for non-aneurysmal SAH) a significantly different clinical outcome was identified compared to aneurysmal SAH. Patients with non-aneurysmal SAH have significantly less DCI compared to aneurysmal SAH, but patients with PM and NPM-SAH also developed DCI. An early hydrocephalus seems not to worsen the outcome, if sufficient and early treated. Patients with a NPM-SAH appear to have an increased risk for DCI and for a worse neurological outcome compared to PM-SAH. However, only a trend towards significance could be calculated. Therefore, patients with a NPM-SAH should be monitored attentively.

\section{Competing interests}

The authors declare that they have no competing interests. The authors have no personal financial or institutional interest in any of the drugs, materials, or devices described in this article.

\section{Authors' contributions}

JK, JP, PS acquired and analyzed the data. JK performed the statistical analysis and drafted the manuscript. JK, EG, HV, VS interpreted the data and contributed to critical revision of the manuscript for important intellectual content. EG performed critical supervision of the manuscript. All authors read and approved the final manuscript.

\section{Acknowledgments}

We thank Marina Heibel and Anne Sicking for excellent technical support.

Received: 31 December 2013 Accepted: 26 June 2014

Published: 1 July 2014

\section{References}

1. van Gijn J, Rinkel GJ: Subarachnoid haemorrhage: diagnosis, causes and management. Brain 2001, 124:249-278.

2. Gupta SK, Gupta R, Khosla VK, Mohindra S, Chhabra R, Khandelwal N, Gupta V, Mukherjee KK, Tewari MK, Pathak A, Mathuriya SN: Nonaneurysmal nonperimesencephalic subarachnoid hemorrhage: is it a benign entity? Surg Neurol 2009, 71:566-571.

3. Ruigrok YM, Rinkel GJ, Buskens E, Velthuis BK, van GJ: Perimesencephalic hemorrhage and CT angiography: a decision analysis. Stroke 2000, 31:2976-2983

4. Bakker NA, Groen RJ, Foumani M, Uyttenboogaart M, Eshghi OS, Metzemaekers JD, Lammers N, Luijckx GJ, Van Dijk JM: Repeat digital subtraction angiography after a negative baseline assessment in nonperimesencephalic subarachnoid hemorrhage: a pooled data meta-analysis. J Neurosurg 2014, 120:99-103.

5. Delgado Almandoz JE, Jagadeesan BD, Refai D, Moran CJ, Cross DT III, Chicoine MR, Rich KM, Diringer MN, Dacey RG Jr, Derdeyn CP, Zipfel GJ: Diagnostic yield of repeat catheter angiography in patients with catheter and computed tomography angiography negative subarachnoid hemorrhage. Neurosurgery 2012, 70:1135-1142.

6. Ildan F, Tuna M, Erman T, Gocer Al, Cetinalp E: Prognosis and prognostic factors in nonaneurysmal perimesencephalic hemorrhage: a follow-up study in 29 patients. Surg Neurol 2002, 57:160-165.

7. van Gijn J, van Dongen KJ, Vermeulen M, Hijdra A: Perimesencephalic hemorrhage: a nonaneurysmal and benign form of subarachnoid hemorrhage. Neurology 1985, 35:493-497.

8. Beseoglu K, Pannes S, Steiger HJ, Hanggi D: Long-term outcome and quality of life after nonaneurysmal subarachnoid hemorrhage. Acta Neurochir (Wien ) 2010, 152:409-416.

9. Kumar S, Goddeau RP Jr, Selim MH, Thomas A, Schlaug G, Alhazzani A, Searls DE, Caplan LR: Atraumatic convexal subarachnoid hemorrhage: clinical presentation, imaging patterns, and etiologies. Neurology 2010, 74:893-899.

10. Kang DH, Park J, Lee SH, Park SH, Kim YS, Hamm IS: Does nonperimesencephalic type non-aneurysmal subarachnoid hemorrhage have a benign prognosis? J Clin Neurosci 2009, 16:904-908.

11. Hui FK, Tumialan LM, Tanaka T, Cawley CM, Zhang YJ: Clinical differences between angiographically negative, diffuse subarachnoid hemorrhage and perimesencephalic subarachnoid hemorrhage. Neurocrit Care 2009, 11:64-70.

12. Renou P, Tourdias T, Fleury O, Debruxelles S, Rouanet F, Sibon I: Atraumatic nonaneurysmal sulcal subarachnoid hemorrhages: a diagnostic workup based on a case series. Cerebrovasc Dis 2012, 34:147-152.

13. Rinkel GJ, Wijdicks EF, Hasan D, Kienstra GE, Franke CL, Hageman LM, Vermeulen $M$, van $G$ J: Outcome in patients with subarachnoid haemorrhage and negative angiography according to pattern of haemorrhage on computed tomography. Lancet 1991, 338:964-968.

14. Vatter H, Guresir E, Berkefeld J, Beck J, Raabe A, du Mesnil de RR, Seifert V, Weidauer S: Perfusion-diffusion mismatch in MRI to indicate endovascular treatment of cerebral vasospasm after subarachnoid haemorrhage. J Neurol Neurosurg Psychiatry 2011, 82:876-883.

15. Vergouwen MD, Vermeulen $M$, van GJ, Rinkel GJ, Wijdicks EF, Muizelaar JP, Mendelow AD, Juvela S, Yonas H, Terbrugge KG, Macdonald RL, Diringer MN, Broderick JP, Dreier JP, Roos YB: Definition of delayed cerebral ischemia after aneurysmal subarachnoid hemorrhage as an outcome event in clinical trials and observational studies: proposal of a multidisciplinary research group. Stroke 2010, 41:2391-2395.

16. Fisher CM, Kistler JP, Davis JM: Relation of cerebral vasospasm to subarachnoid hemorrhage visualized by computerized tomographic scanning. Neurosurgery 1980, 6:1-9.

17. Maslehaty H, Petridis AK, Barth H, Mehdorn HM: Diagnostic value of magnetic resonance imaging in perimesencephalic and nonperimesencephalic subarachnoid hemorrhage of unknown origin. J Neurosurg 2011, 114:1003-1007.

18. Nayak S, Kunz AB, Kieslinger K, Ladurner G, Killer M: Classification of non-aneurysmal subarachnoid haemorrhage: $\mathrm{CT}$ correlation to the clinical outcome. Clin Radiol 2010, 65:623-628.

19. Pyysalo LM, Niskakangas TT, Keski-Nisula LH, Kahara VJ, Ohman JE: Long term outcome after subarachnoid haemorrhage of unknown aetiology. J Neurol Neurosurg Psychiatry 2011, 82:1264-1266.

20. Rinkel GJ, Wijdicks EF, Vermeulen M, Hasan D, Brouwers PJ, van GJ: The clinical course of perimesencephalic nonaneurysmal subarachnoid hemorrhage. Ann Neurol 1991, 29:463-468.

21. Canhao P, Ferro JM, Pinto AN, Melo TP, Campos JG: Perimesencephalic and nonperimesencephalic subarachnoid haemorrhages with negative angiograms. Acta Neurochir (Wien) 1995, 132:14-19.

22. Garcia-Rodriguez LA, Gaist D, Morton J, Cookson C, Gonzalez-Perez A: Antithrombotic drugs and risk of hemorrhagic stroke in the general population. Neurology 2013, 81:566-574.

23. van der Worp HB, Fonville S, Ramos LM, Rinkel GJ: Recurrent perimesencephalic subarachnoid hemorrhage during antithrombotic therapy. Neurocrit Care 2009, 10:209-212.

24. Naidech AM, Rosenberg NF, Maas MB, Bendok BR, Batjer HH, Nemeth AJ: Predictors of hemorrhage volume and disability after perimesencephalic subarachnoid hemorrhage. Neurology 2012, 78:811-815. 
25. Dalyai R, Chalouhi N, Theofanis T, Jabbour PM, Dumont AS, Gonzalez LF, Gordon DS, Rosenwasser RH, Tjoumakaris SI: Subarachnoid hemorrhage with negative initial catheter angiography: a review of 254 cases evaluating patient clinical outcome and efficacy of short- and long-term repeat angiography. Neurosurgery 2013, 72:646-652.

26. Jung JY, Kim YB, Lee JW, Huh SK, Lee KC: Spontaneous subarachnoid haemorrhage with negative initial angiography: a review of 143 cases. J Clin Neurosci 2006, 13:1011-1017.

27. Khan AA, Smith JD, Kirkman MA, Robertson FJ, Wong K, Dott C, Grieve JP, Watkins LD, Kitchen ND: Angiogram negative subarachnoid haemorrhage: outcomes and the role of repeat angiography. Clin Neurol Neurosurg 2013, 115:1470-1475.

28. Boswell S, Thorell W, Gogela S, Lyden E, Surdell D: Angiogram-negative subarachnoid hemorrhage: outcomes data and review of the literature. J Stroke Cerebrovasc Dis 2013, 22:750-757.

29. Broderick JP, Brott TG, Duldner JE, Tomsick T, Leach A: Initial and recurrent bleeding are the major causes of death following subarachnoid hemorrhage. Stroke 1994, 25:1342-1347.

30. Yu DW, Jung YJ, Choi BY, Chang CH: Subarachnoid hemorrhage with negative baseline digital subtraction angiography: is repeat digital subtraction angiography necessary? I Cerebrovasc Endovasc Neurosurg 2012, 14:210-215.

31. Kelliny M, Maeder P, Binaghi S, Levivier M, Regli L, Meuli R: Cerebral aneurysm exclusion by $\mathrm{CT}$ angiography based on subarachnoid hemorrhage pattern: a retrospective study. BMC Neurol 2011, 11:8.

32. Whiting J, Reavey-Cantwell J, Velat G, Fautheree G, Firment C, Lewis S, Hoh B: Clinical course of nontraumatic, nonaneurysmal subarachnoid hemorrhage: a single-institution experience. Neurosurg Focus 2009, 26:E21.

33. Woznica M, Rosahl SK, Berlis A, Weyerbrock A: Outcome correlates with blood distribution in subarachnoid hemorrhage of unknown origin. Acta Neurochir (Wien) 2010, 152:417-422.

34. Samaniego EA, Dabus G, Fuentes K, Linfante I: Endovascular treatment of severe vasospasm in nonaneurysmal perimesencephalic subarachnoid hemorrhage. Neurocrit Care 2011, 15:537-541.

35. Molyneux A, Kerr R, Stratton I, Sandercock P, Clarke M, Shrimpton J, Holman R International Subarachnoid Aneurysm Trial (ISAT) of neurosurgical clipping versus endovascular coiling in 2143 patients with ruptured intracranial aneurysms: a randomised trial. Lancet 2002, 360:1267-1274.

36. Spetzler RF, McDougall CG, Albuquerque FC, Zabramski JM, Hills NK, Partovi S, Nakaji $P$, Wallace RC: The barrow ruptured aneurysm trial: 3-year results. J Neurosurg 2013, 119:146-157.

37. Rivero-Arias O, Wolstenholme J, Gray A, Molyneux AJ, Kerr RS, Yarnold JA, Sneade M: The costs and prognostic characteristics of ischaemic neurological deficit due to subarachnoid haemorrhage in the United Kingdom. Evidence from the MRC International Subarachnoid Aneurysm Trial. J Neurol 2009, 256:364-373.

doi:10.1186/1471-2377-14-140

Cite this article as: Konczalla et al:: Non-aneurysmal non-traumatic subarachnoid hemorrhage: patient characteristics, clinical outcome and prognostic factors based on a single-center experience in 125 patients. BMC Neurology 2014 14:140.

\section{Submit your next manuscript to BioMed Central and take full advantage of:}

- Convenient online submission

- Thorough peer review

- No space constraints or color figure charges

- Immediate publication on acceptance

- Inclusion in PubMed, CAS, Scopus and Google Scholar

- Research which is freely available for redistribution 